\title{
Mapping the dynamics of urban land creation from hilltop removing and gulley filling projects in the river-valley city of Lanzhou, China
}

Niu quanfu ( $D$ 330398304@qq.com )

Lanzhou university of techology https://orcid.org/0000-0001-5831-7260

Jianrong Bei

Gansu Institute of Survey and Maping

Weiming Cheng

CAS

Xinghai Dang

Lanzhou University of Technology

Guigang Wang

Lanzhou Jiaotong University

Xiaolong Gao

Gansu institute of survering and mapping

Yijun Wang

Gansu institue of Surveying and Mapping

\section{Research Article}

Keywords: land reclamation, plot, remote sensing monitoring, center, indicator

Posted Date: March 16th, 2021

DOI: https://doi.org/10.21203/rs.3.rs-196283/v1

License: (9) This work is licensed under a Creative Commons Attribution 4.0 International License.

Read Full License 


\title{
Mapping the dynamics of urban land creation from hilltop removing and gulley filling projects in the river-valley city of Lanzhou, China
}

Quanfu Niu ${ }^{1,2}$, Jianrong Bai ${ }^{3}$, Weiming Cheng ${ }^{4}$, Xinghai Dang ${ }^{1,2}$, Guigang Wang ${ }^{3}$, Xiaolong Gao ${ }^{3}$, Yijun Wang ${ }^{3}$

1. School of Civil Engineering, Lanzhou University of Technology, Lanzhou 730050, PR China

2. Emergency Mapping Engineering Research Center of Gansu Province, Lanzhou 730050, PR China

3. Gansu institute of Surveying and Mapping, Lanzhou, 730000, PR China

4. State Key Laboratory of Resources and Environmental Information System, Institute of Geographic Sciences and Natural Resources Research, CAS, Beijing 100101, PR China

\begin{abstract}
To expand urban area and protect farmland effectively, Hilltop Removing and Gulley Filling Projects (HRGFP) in the river-valley city of Lanzhou, China have been carried out over the last decades. However, monitoring the dynamic characteristic and scale of the projects and the impact on the local ecoenvironment caused by HRGFP is necessary. Here, we conducted field investigations and used aerial remote sensing images and the Spatial Expansion Intensity Index (SEII), Terrain Niche Index (TNI), Biophysical Composition Index (BCI), and Remote Sensing Environment Index (RSEI) to monitor the dynamic characteristics of new plots and changes in the local environment. The total area of the new plots from HRGFP around Lanzhou was about $203.18 \mathrm{~km}^{2}$ in 1989-2016 with a continuous shift away from the urban area to the low hills, gentle slopes, and gullies in the north, which has greatly enlarged the urban area and increased economic development. We found that the new plots were converted to new forest and grassland in addition to buildings. RSEI indicated that the environment quality improved in $3984 \mathrm{~km}^{2}$ of the study area, or $55.73 \%$ of the total area, after a short period of degradation. Our results indicated that HRGFP in Lanzhou have enlarged the urban area and increased economic development, and improved environment under the guidance of the local government.
\end{abstract}

\section{Key words}

land reclamation, plot, remote sensing monitoring, center, indicator 


\section{Introduction}

As a scarce natural resource, land cannot be used by human beings without limitation because of its fixed location and limited area (Fischer et al., 2012; Steduto et al., 2012). In China, the national land survey shows that by the end of October 2006, the total area of farmland in the country was about $121.8 \mathrm{M}$ hectares and per capita farmland area is less than 0.093 hectares, which is only $40 \%$ of the world average area (Wen, 2016; Yang and Wang, 2014). Therefore, the Chinese government stipulated that the farmland area of $120 \mathrm{M}$ hectares is "red line" and nobody can change its use. With the development of China's economy and the advancement of urbanization, there is an inevitable contradiction between the scarcity of land resources and the growing economy, especially in cities with limited topographic expansion such as Lanzhou, Yan'an, and Shiyan. The main problem faced by local governments is how to provide the land necessary for economic development without breaking through the threshold of 120M hectares of farmland. In addition to saving land and improving the efficiency of existing land use, the gradual development and utilization of unused land around these cities is a way out of urban space development supported by the local governments (Hang et al., 2009; Li et al., 2014; Liu et al., 2016; Liu and Li, 2014; Liu et al., 2013; Wen et al., 2018).

In recent years, China is experiencing a boom in city-building, and the city-building of Lanzhou in the mountainous area also reflects the process of urbanization in China. As a typical river-valley city, Lanzhou roads are crowded and air pollution is serious, and the narrow space between the north and the south severely restricts urbanization. However, there are about $7.618 \times 10^{3} \mathrm{~km}^{2}$ of unused land around Lanzhou such as barren hills, gentle slopes, and gullies, accounting for $57 \%$ of its total area. Therefore, in the 1990s, the local government has focused on developing the surrounding barren mountains, some of which have been leveled. In 2007, the Lanzhou government began to actively promote the comprehensive development and utilization of unused land. In 2012, with the approval of the Ministry of Land and Resources of China (Li et al., 2020; Pu et al., 2016), Hilltop Removing and Gulley Filling Projects (HRGFP) were initiated. The projects have mainly included bulldozing about 700 hills to fill in valleys and creating flat lands for urban land development and ecological improvement by converting barren land to forest and grassland.

These large geotechnical projects in the collapsible Loess area in the world ( $\mathrm{Li}$ et al., 2014) have

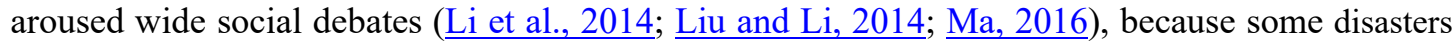
have been taken place in several land creation regions in China. For example, the land creation projects in Shiyan have caused some landslides and floods in 2007 ( $\mathrm{Ma}, 2016)$, the surface subsidence in Yan'an new urban region was caused by heavy rainfall in April 2012 (Yang et al., 2016), and the Shennongjia airport project impacted the surrounding ecological environment due to a lack of an

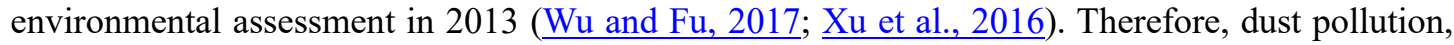
vegetation destruction, geological structure change, and Loess subsidence are also the main problems faced by HRGFP in Lanzhou (Li et al., 2014; Liu and Li, 2014; Ma, 2016). However, other views argued that HRGFP in Lanzhou were based on the full evaluation of experts from the fields of geology, hydrology, soil and water conservation, as well as many engineering tests and government planning. Thus, it is argued that the aforementioned problems in Lanzhou can be completely eliminated through engineering and technology ( $\underline{\mathrm{Liu}}$ and Li, 2014; $\underline{\text { Ma, 2016; Zhang et }}$ al., 2009). Among these debates and views, the biggest challenge is how to monitor the changes and impacts caused from HRGFP rather than theoretical and hypothetical debate.

Recently, remote sensing technology has been widely used to monitor and classify land use and 
Land cover change (LUCC) and evaluate environmental changes (Hassan et al., 2016; Olorunfemi et al., 2018; Zoungrana et al., 2015). Long-term, time-series Satellite images with different spatial resolutions have been successfully used to identify land types via various classification and dynamic change analysis (Green et al., 1994; Liu et al., 2015; Mundia and Aniya, 2005; Niu et al., 2019). Several ecological indicators, such as Spatial Expansion Intensity Index (SEII) (Al-Sharif et al., 2014; Zhou and He, 2006), Terrain Niche Index (TNI) (Rao et al., 2007; Yu et al., 2001), Biophysical Composition Index (BCI) (Deng and Wu, 2012), and Remote Sensing Environmental Index (RSEI) (Li et al., 2015) have been used to monitor and evaluate environmental change. Therefore, using remote sensing big data technology with suitable algorithms can well monitor the spatial-temporal characteristics and impacts of HRGFP projects.

With the rapid development of HRGFP in Lanzhou, it is necessary to monitor where the HRGFP sites were, how many new plots were created, and how much influence HRGFP caused on local eco-environment. Therefore, the main objective of this study was to (a) map urban land reclamation with multi-source remote sensing data for 1989-2016, (b) explore the annual spatial change characteristics of new urban land, and (c) quantify the influence of HRGFP on the local ecoenvironment.

\section{Materials and Methods}

\subsection{Study area}

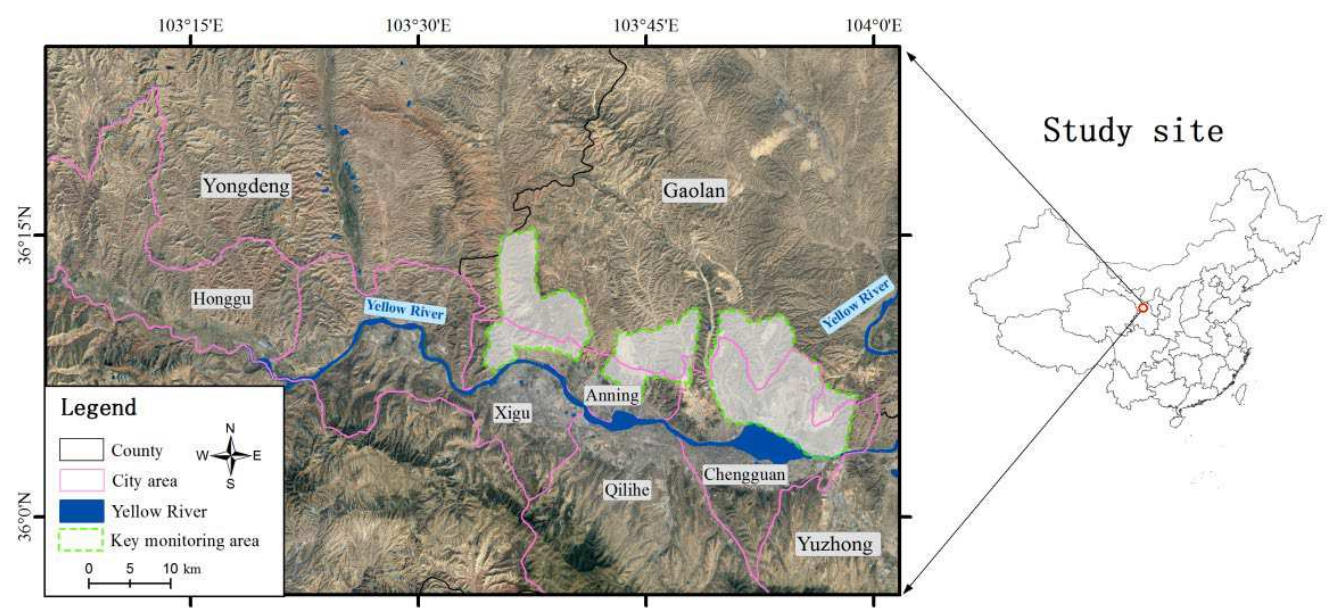

Fig.1 Study area (mainly including three counties (Yongdeng, Gaolan, and Yuzhong) and five districts (urban area: including Chengguan, Qilihe, Anning, Xigu, and Honggu). The areas with a green line are the key monitoring areas, from west to east are Shazhong-Shengou, Yanchi-Maocha-Jiuzhou, and Qingshi, respectively.)

Lanzhou City, the provincial capital of Gansu province, is located on the upper reaches of the Yellow River in Northwest China, and includes three counties (Yongdeng, Yuzhong, and Gaolan) and five districts(Chengguan, Qilihe, Anning, Xigu, and Honggu) (Fig.1). As a geographic center of China's land territory (Niu et al., 2010; Yu et al., 2009), it has a long history and splendid culture. However, East China is developed, and Western backwardness is a real problem. In recent years, to further develop its weak economy, the policies of developing and constructing the economy of the western region have been implemented by the Chinese government, and Lanzhou is also facing unprecedented opportunities. Surrounded by mountains in the north and south, and with the Yellow 
River passing through the city from west to east, Lanzhou has the characteristics of an urban rivervalley basin with extremely limited space for expansion. With the rapid growth of the urban population, the shortage of land for urban construction has seriously limited the development and improvement of the function of the city, resulting in a series of social problems, such as the excessive population density, air pollution, serious traffic jams, and rapid increases in the cost of housing. Therefore, to develop the economy and protect farmland, it has been effective for Lanzhou to expand the urban area towards the unused low hills, gentle slopes, and gullies. Because of the higher mountains, deeper valleys, and limited unused land in its south, the main sites for land creation in Lanzhou are in the mountainous area to the north, which was mostly low loess hills, gentle slopes, and intermountain basins. And in recent years, land creation projects in these sites are booming. To further quantify the plots caused by land creation projects, we also focused three key monitoring areas, Shazhong-Shengou, Yanchi-Maocha-Jiuzhou, and Qingshi.

\subsection{Data}

\section{1) Aerial image data}

The aerial image datasets mainly include digital elevation model (DEM) and digital orthophoto map (DOM), which were produced by Gansu Surveying and Mapping Geographic Information Bureau (GSMGIB) of China with full digital photogrammetry technology and covered the entire study area. Aerial images from three periods were used to monitor the changes from the landcreation projects. The images from the first period were taken by an RC-10A camera in July 2000 with photographic scale of 1:35,000. After drawing maps, the resolution of Grid-DEM is $12 \mathrm{~m}$, the ground resolution of DOM is $1 \mathrm{~m}$, and the DLG data consists only of contour, elevation points, and annotations of toponym. The images from the second period were taken from July to December 2010 with an Airborne Digital Senor 80 (ADS80). The ground resolution of its true color DOM is $1 \mathrm{~m}$ and the resolution of Grid-DEM is $5 \mathrm{~m}$. The images form the third period were taken from May to September 2016 with ADS100. The DOM is true color, with ground resolution of $0.5 \mathrm{~m}$ and GridDEM of $5 \mathrm{~m}$. All these data sets were in the 2000 national geodetic coordinate system and the 1985 national elevation base.

\section{2) National geoinformation survey dataset}

The national geoinformation survey dataset mainly includes DEM, land cover, the spatial distribution of resources, and economic data, which is an important part of the basic national geoinformation data ( $\mathrm{Li}$ et al., 2018). To meet the needs of economic and social development as well as ecological conservation, the Chinese government decided to carry out the first national geoinformation survey project (NGSP) in January 2013 and it lasted three years. Its purpose was to systematically obtain authoritative, objective, and accurate information on the geographic conditions of the country in order to provide an important foundation for promoting ecological environmental protection and building a resource conserving and environmentally friendly society (Li et al., 2018). Using the global navigation satellite system (GNSS), remote sensing (RS), geoinformation system (GIS), and other modern surveying and mapping technologies, the national geoinformation survey dataset was dynamically and quantitatively obtained, and mainly formed three types of key data: land topography (including DEM, slope, and aspect), LULCC (including 10 major classes, such as farmland, garden land, and forestland), and social geographical units (including educational facilities, hospitals, administrative units, boundaries, and other urban 
integrated functional units). The greatest advantage of the dataset is that it is highly accurate with a spatial resolution of $0.5 \mathrm{~m}$ and provides useful information for the local government to promote ecological environmental protection and disaster prevention and mitigation.

\section{3) Remote sensing data}

We used long-term Landsat data for 1989-2016 to monitor the spatial-temporal distribution of new land reclamation every year in study area as well as environmental change. Due to the Landsat7 ETM+ data gap caused by Scan Line Corrector (SLC) after 2003, we used Landsat5 TM data in 1989-1998 and 2003-2010, and Landsat7 ETM+ in 1999-2002. Landsat7 ETM+ data in 2011-2012 were used after data gap processing in ENVI5.0. We used Landsat8 OLI data for 2013-2019. The three Landsat datasets were downloaded from https://www.gscloud.cn/ and https://earthexplorer.usgs.gov/, respectively. The preprocessing mainly included radiometric calibration, atmospheric correction, and geometric correction. Among them, we selected one period of Landsat data from spring or autumn every year and in total 32 images were chosen to obtain the spatial-temporal distribution of new plots caused by HRGFP.

\section{4) Inventory data}

The expansion of the main urban area in Lanzhou is limited, and the population density of the built-up areas is much higher than in other cities in China (Pan, 2016). Hence, seeking urban expansion space is always a very urgent task for local government. We used inventory data from three sources in our study. The primary inventory data came from the General Plan for the Comprehensive Development and Utilization of Unused Land compiled (2012-2030) by the Lanzhou Bureau of Land and Resources in 2012. It includes low hills, gentle slopes, and gullies of Lanzhou, a five-year plan for national economic and social development, and the overall plans of land use and urban construction (General Office of Lanzhou Municipal People's Government, 2014). The plan divided the entire land-creation region into six areas, included three key monitoring areas (Shazhong-Shengou, Yanchi-Maocha-Jiuzhou, and Qingshi) (Fig.1). The second data source was the Overall Planning of Lanzhou City (2011-2020) (General Office of Lanzhou Municipal People's Government, 2016) and Land Use Data of Lanzhou, completed in 2016, which were used to analyze land use and land cover change (LULCC) during the period of land-creation projects. The third source was statistical yearbooks, including the Development Yearbook of Gansu Province, Statistical Yearbook of Gansu Province, and the Population Statistics Yearbook of Lanzhou City, which were mainly used for monitoring the spatial and temporal changes of the landscape surface and analyzing its driving factors.

\subsection{Methods}

\subsubsection{Interpretation of the new plots formed by HRGFP}

The new plots formed by HRGFP were interpreted from the aerial images with higher spatial resolution of $0.2 \mathrm{um}$ processed by photogrammetry technology. In our study, only the new urban plots with an area larger than $2000 \mathrm{~m}^{2}$ were counted. In order to obtain the new plots with consistent spatial position, we used the data set produced in 2016 as a benchmark, those produced in 2000 and 2010 were processed with polynomial geometry correction and resampling based on the dataset in 2016.

In the study region, the main terrain features are hilly and mountainous, and the sites of land creation were mainly located at the junction of flats and hills (slope $\geq 3^{\circ}$ ). Based on on-site surveys, 
the ranges of plots were extracted as follows. First, we roughly painted the boundary of the new plots at the junction of hills and flats based on the DEM and DOM from 2000. Second, the approximate plots were verified by the difference images of DEMs in two periods using the software ArcGIS10.2, that is, the DEM difference images were calculated from 2010 to 2000 and 2016 to 2010, respectively. Third, we checked its boundaries by overlaying the DOMs in 2010 and 2016 and further revised them. Finally, the area of new urban plots was calculated, and the attributions were identified.

\subsubsection{Monitoring annual spatial distribution of new urban plots}

The annual spatial distribution of HRGFP plots was monitored using Landsat images in 19892016. Due to its resolution, we mainly used these images to extract the spatiotemporal distribution of new urban plots in study area. First, we projected Landsat images into China Geodetic Coordinate System in 2000 (CGCS2000) and corrected with the DOM from 2016. We used false color images composited using the near infrared (NIR), red, and green bands of Landsat data to extract the yearly spatial plots using visual interpretation with ENVI and ArcGIS10.2 (Fisher et al., 2016). The specific methods are as follows. We first superimposed the image of 1990 on the image of 1989 , and the spatial plot from land creation in 1989-1990 was extracted by visual interpretation. Then, the spatial plot in 1989-1990 were overlaid on the 1991 image to extract the spatial plot in 19901991. We repeated this process sequentially from 1992 to 2016 to develop annual change maps. We simultaneously further corrected the error using the three-period aerial images $(2000,2010$, and 2016) and Google Earth online images.

\subsubsection{Spatial-temporal change analysis for LULCC}

The LULCC data for our study area were classified by artificial interpretation from threeperiod DOMs (2000, 2010, and 2016), including farmland, grassland, garden land, forest, building, road, structure, bare land, and water. To analyze the features of LULCC in study area caused by HRGFP, three parameters (transfer matrix, spatial expansion intensity index(SEII), and terrain niche index(TNI)) were calculated to quantitatively analyze the spatial-temporal changes of LULCC.

1) Transfer matrix is a form to show the conversion relationship between land cover types in two periods, and reflects the dynamic change among different land cover types (Chen et al., 2018; Moulds et al., 2015). The main expression is as follows:

$$
p_{i j}=\left[\begin{array}{ccc}
p_{11} & \cdots & p_{1 n} \\
\vdots & \ddots & \vdots \\
p_{n 1} & \cdots & p_{n n}
\end{array}\right]
$$

Where, $p_{i j}$ is the area of the land cover type $i$ converted to the land cover type $j . \mathrm{n}$ is the number of the land cover types.

2) Because of the complexity and multi-directionality of LULCC, we used the spatial expansion intensity index(SEII) to express its dynamic change, and predict its future change (AlSharif et al. 2014; Zhou and He 2006). The SEII can be calculated as follows:

$$
\begin{aligned}
& \beta_{1}=\frac{\left[\frac{\left(K L A_{i, t+n}-U L A_{i, t}\right)}{n}\right]}{T L A_{t}} \times 100 \% \\
& \beta_{2}=\frac{\left[\frac{\left(W L A_{i, t+n}-U L A_{i, t}\right)}{n}\right]}{T L A_{t}} \times 100 \% \\
& N L A_{i, t+n}=K L A_{i, t+n}+U L A_{i, t}-W L A_{i, t+n}
\end{aligned}
$$


Where, $\beta_{1}$ is the annual average expansion intensity of a land type $i . \beta_{2}$ is the annual average contraction intensity of a land type $i . K L A_{i, t+n}$ is the annual expansion area of the land type $i$ during $\mathrm{t}+\mathrm{n}$ years. $W L A_{i, t+n}$ is the annual contraction area of the land type $i$ during $\mathrm{t}+\mathrm{n}$ years. $T L A_{t}$ is the total land types area in t year. $U L A_{i, t}$ is the area of the land type $i$ in t years. $N L A_{i, t+n}$ is the total area of the land type $\mathrm{i}$ in $\mathrm{t}+\mathrm{n}$ years.

To further analyze the trend of LULCC, SEII is graded according to the following rules:

(1) $-1<\beta_{1}+\beta_{2}<-0.4$ and $\left|\beta_{1}-\beta_{2}\right| \geq 0.1$, Relative stability

(2) $\beta_{1}+\beta_{2}<-1$ and $-0.1<\beta_{1}-\beta_{2}<-0.01$, Slower contraction

(3) $\beta_{1}+\beta_{2}<-1$ and $\beta_{1}-\beta_{2}<-0.1$, Rapid contraction

(4) $\beta_{1}+\beta_{2}>-0.4$ and $-0.01<\beta_{1}-\beta_{2}<0.1$, Slower expand

(5) $\beta_{1}+\beta_{2}>-0.4$ and $\beta_{1}-\beta_{2}>0.1$, Rapid expand

3) The constraints of terrain conditions on land use are often affected by the combination of slope and elevation. In order to comprehensively reflect the spatial differentiation of land use change in terrain conditions, we use the geographic information modeling method to combine the elevation and slope into a terrain niche index (TNI) (Rao et al., 2007; Yu et al., 2001), and quantitatively analyze the relationship between LULC and the terrain conditions. Its formula is as follows:

$$
T N I=\log \left[\left(\frac{E}{\bar{E}}+1\right)\left(\frac{S}{\bar{S}}+1\right)\right]
$$

Where, $\mathrm{E}$ and $\overline{\mathrm{E}}$ represent elevation and average elevation of any point in study region,

respectively. $\mathrm{S}$ and $\overline{\mathrm{S}}$ represent slope and average slope, respectively. A point with higher the elevation and slope, its TNI is the bigger.

\subsubsection{Environmental change analysis}

Greenness, wetness, and dryness are important indicators that are often used to evaluate the quality or condition of vegetation (Gupta et al., 2012; Jing et al., 2020). In this study, we used the Normalized Difference Vegetation Index (NDVI), calculated from near infrared and red bands of Landsat images to represent greenness because it is closely related to vegetation coverage, leaf area index, and photosynthetic capacity (Pettorelli et al., 2005). The components of brightness, greenness, and wetness from Tasseled Cap Transformation (TCT) have been extensively used in ecological monitoring studies. Therefore in our study the wetness indicator was TCT calculated from satellite images (Landsat5 TM and Landsat8 OLI) (Baig et al., 2014). Heat is expressed by Land Surface Temperature (LST) which was inverted by brightness temperature and ratio radiation (Dobrovolný, 2013). The heat of Landsat5 TM images is obtained from land surface temperature (Sobrino et al., 2004), and the heat of Landsat8 OLI images is obtained from the Atmospheric Correction Parameter Calculator (NASA, 2016; Yu et al., 2014). Based on the date and time of the satellite overpass and the geographical location, we computed the LST data of the study area.

Due to lower vegetation cover and intense human activities in our study area, we used the Biophysical Composition Index (BCI) as dryness indicator, which can combine information on bare soil and urban impervious surface and is more suitable for monitoring ecological environment of the dryness and low vegetation coverage area (Deng and $\mathrm{Wu}, 2012$ ). The BCI was calculated as follows. First, we identified water pixels and masked out using an unsupervised classification. Second, brightness, greenness, and wetness were linearly normalized within the range from 0 to 1 
after carrying out the function of TCT. Then, the BCI was calculated using eq.(6).

$$
\mathrm{BCI}=[0.5(\mathrm{H}+\mathrm{L})-\mathrm{V}] /[0.5(\mathrm{H}+\mathrm{L})+\mathrm{V}]
$$

where, $\mathrm{H}$ is "high albedo", normalized brightness; $\mathrm{L}$ is "low albedo", normalized wetness; and V is "vegetation", normalized greenness.

Finally, the Remote Sensing Environmental Index (RSEI) was calculated by integrating the four indicators via Principal Component Analysis (PCA) rather than a traditional weighted method. Because each indicator has a different unit and data range, it is necessary to normalize the values of the four indicators to within [0,1] before PCA performed. RSEI can be expressed as a function of the four normalized indicators and the original ecological index is obtained from the result of the

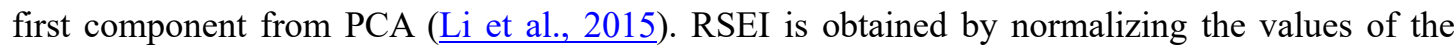
original ecological index within $[0,1]$. When the value of RSEI is closer to 1 , the ecological environment quality is better. On the hand, when the value of RSEI is closer to 0 , the ecological environment quality is poor.

\section{Results}

\subsection{Spatial-temporal dynamics of new land reclamation}

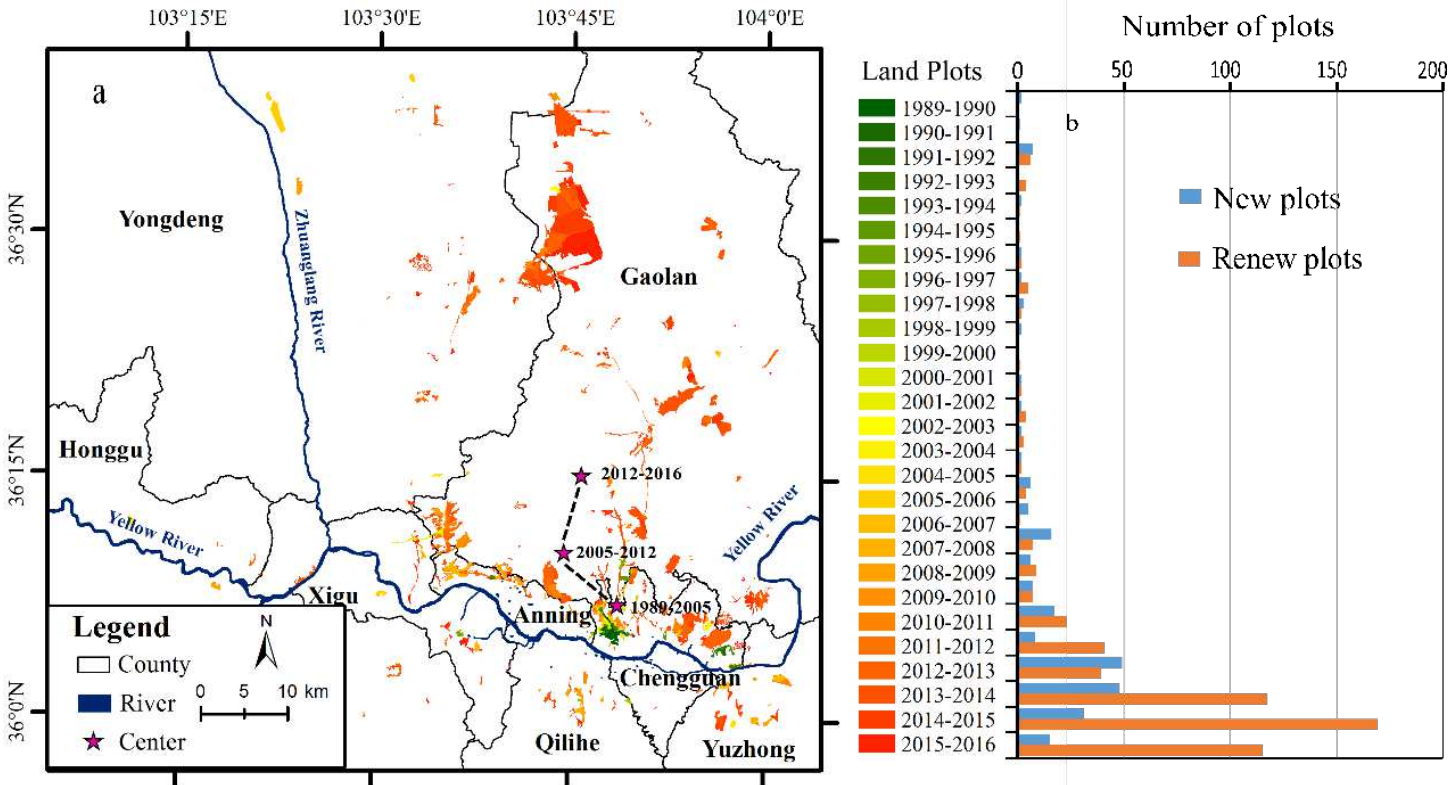

Fig.2 Spatial-temporal distribution and statistics of new land reclamation in 1989-2016 (a, Spatial distribution, three stars from south to north express the centers of new plots in 1989-2005, 2006-2012 and 2013-2016, respectively. $b$, The number of new and renew urban plots)

The plots of new land reclamation obtained by remote sensing images, aerial images, and in situ data were scattered over the study area in 1989-2016 (Fig.2a). Most of new urban plots were in the low hills and gentle slopes north of the Yellow River, and some also were found in narrow gullies and valleys in the south. According to the local government policies and the process of HRGFP, the 1989-2016 period was divided into three stages, 1989-2005, 2005-2012 and 2012-2016. Before 2005, the HRGFP sites were mostly near urban Lanzhou and we found from field investigation that most of them were originally man-made piling and digging plots, whose area is about $14.1 \mathrm{~km}^{2}$ with average annual growth speed of $0.875 \mathrm{~km}^{2} / \mathrm{a}$. In this stage, the scale is small with a feature of single- 
center expansion mode. In 2005-2012, the HRGFP sites gradually moved northward and were mainly located in the low hills and gentle slopes around the city with very little vegetation cover. In this period, the scale of HRGFP is three times the area of the first stage (1989-2005) with an average annual expansion rate of $6.702 \mathrm{~km}^{2} / \mathrm{a}$ and multi-center expansion mode. During the third stage (2012-2016), the HRGFP projects expanded rapidly with bare land area being about $144.01 \mathrm{~km}^{2}$ with an average annual expansion speed of $36.003 \mathrm{~km}^{2} / \mathrm{a}$. It also showed that the new plots first increased and then decreased, while the renewed plots on the original plots continuously increased (Fig.2b), especially in 2013-2014 when the area reached a maximum. Although the total area of new urban land reclamation in 2015-2016 decreased by $26.3 \mathrm{~km}^{2}$ compared with that in $2013-2014$, it was still far larger than before 2012, and most of them are renewed plots, accounting for $72.4 \%$ of the area.

The new urban land reclamation in 1989-2016 also showed obvious differences in space and scale. To further analyze the change plots from HRGFP, we calculated the distributional centers in 1989-2005, 2006-2012, and 2013-2016, respectively. It showed that from the first (1989-2005) to second (2006-2012) stage, the center shifted $8.6 \mathrm{~km}$ northwest. After the third stage, the centers shifted $9.1 \mathrm{~km}$ northeast. During the study period, the center of HRGFP generally showed a trend of continuous shift from south to north, and shifted $15.5 \mathrm{~km}$ northwest (Fig.2a).

\subsection{LULCC transfer analysis in 2000-2017}

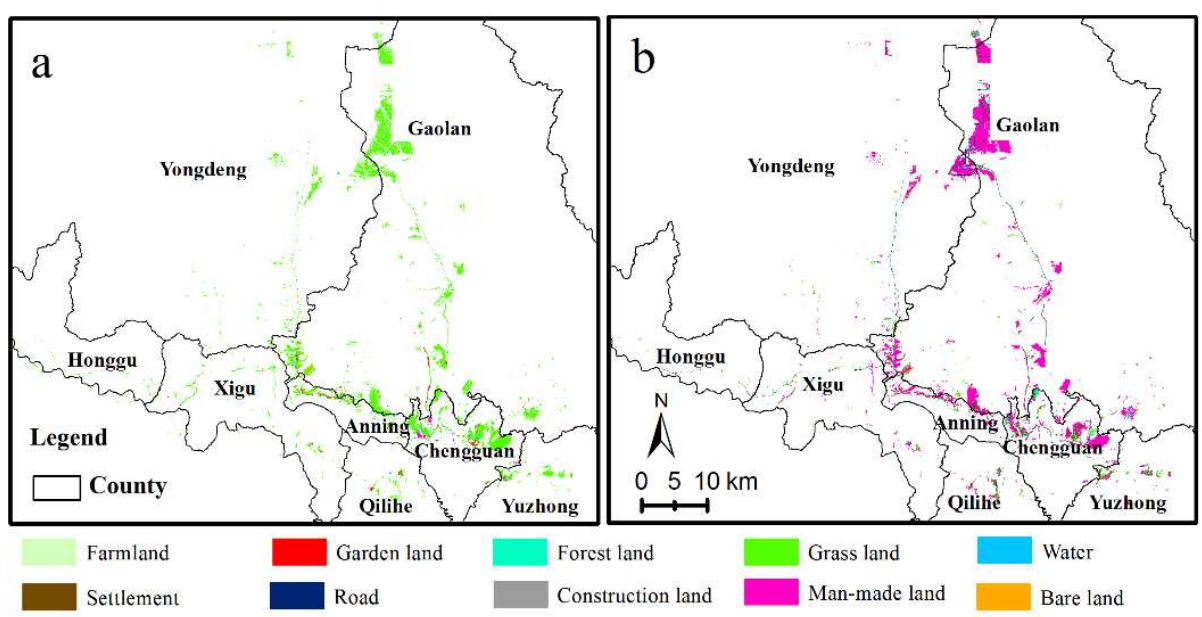

Fig.3 LULCC transfer and distribution in 2000-2017
(a), LULCC before 2010;
(b), LULCC after 2010

Before 2000 in study area, LULC occurred mainly in low-cover grassland and dry farmland. Grassland was the largest land cover type with an area of $122.47 \mathrm{~km}^{2}$, which mainly were on the barren hills, and accounted for $75.98 \%$ of the study region. Dry farmland, with an area of $27.48 \mathrm{~km}^{2}$ and accounting for $17.05 \%$ of the region, were mostly distributed in the smaller gully flats. The proportion of man-made piling and digging land, garden land, and forest only were about $1 \% \sim 2 \%$. The areas of other land cover types, such as construction land, roads, bare land, and water were less (Fig.3a, Table 1).

During 2000-2017, the most common type of land cover was man-made, which obviously was converted from other land types, such as grassland and farmland, and accounted for $63.05 \%$ of the region. The second type was grassland, accounting for $11.10 \%$, which were mainly from artificial planting on man-made land after HRGFP and from abandoned land after HRGFP. The structures 
mainly were the hardened revetment on both sides of the highway and railway and accounted for $8.10 \%$ of the region. Roads (including highway and railway) accounted for $6.98 \%$. Buildings (including residential buildings, offices of industrial and mining enterprises, etc.) accounted for $4.39 \%$. In addition, the land types with very small areas were garden land, forest, and water area (Fig.3b, Table 1).

From 2000, the land cover type with the largest loss of area was grassland with an area of 104.69

344 $\mathrm{km}^{2}$. The second was farmland and garden land, among which the farmland area decreased by 24.97 $\mathrm{km}^{2}$ and garden land area decreased by $1.61 \mathrm{~km}^{2}$. The land type with the largest increase in area was man-made land, which increased by $96.97 \mathrm{~km}^{2}$. Other land cover types with an increase in area were from large to small was structures, roads, buildings, and forest. During this time, there was little area change for bare land and water (Table 1).

Table1 Area and proportion of LULCC in 2000 and 2017

\begin{tabular}{cccccc}
\hline \multirow{2}{*}{ Land types } & \multicolumn{2}{c}{ Area $\left(\mathrm{km}^{2}\right)$} & \multicolumn{2}{c}{ Percentage $(\%)$} & \multirow{2}{*}{$\Delta$ Area $(\mathrm{km} 2)$} \\
\cline { 2 - 5 } & 2000 & 2017 & 2000 & 2017 & \\
\hline Farmland & 27.48 & 2.51 & 17.05 & 1.56 & -24.97 \\
Garden land & 2.47 & 0.86 & 1.53 & 0.54 & -1.61 \\
Forest & 1.8 & 4.71 & 1.12 & 2.94 & 2.91 \\
Grassland & 122.47 & 17.78 & 75.98 & 11.10 & -104.69 \\
Building & 0.43 & 7.03 & 0.27 & 4.39 & 6.60 \\
Road & 0.37 & 11.19 & 0.23 & 6.98 & 10.82 \\
Structure & 0.76 & 12.98 & 0.47 & 8.10 & 12.22 \\
Man-made land & 4.06 & 101.03 & 2.52 & 63.05 & 96.97 \\
Bare land & 1.21 & 1.29 & 0.75 & 0.80 & 0.08 \\
Water & 0.13 & 0.88 & 0.08 & 0.55 & 0.75 \\
\hline
\end{tabular}
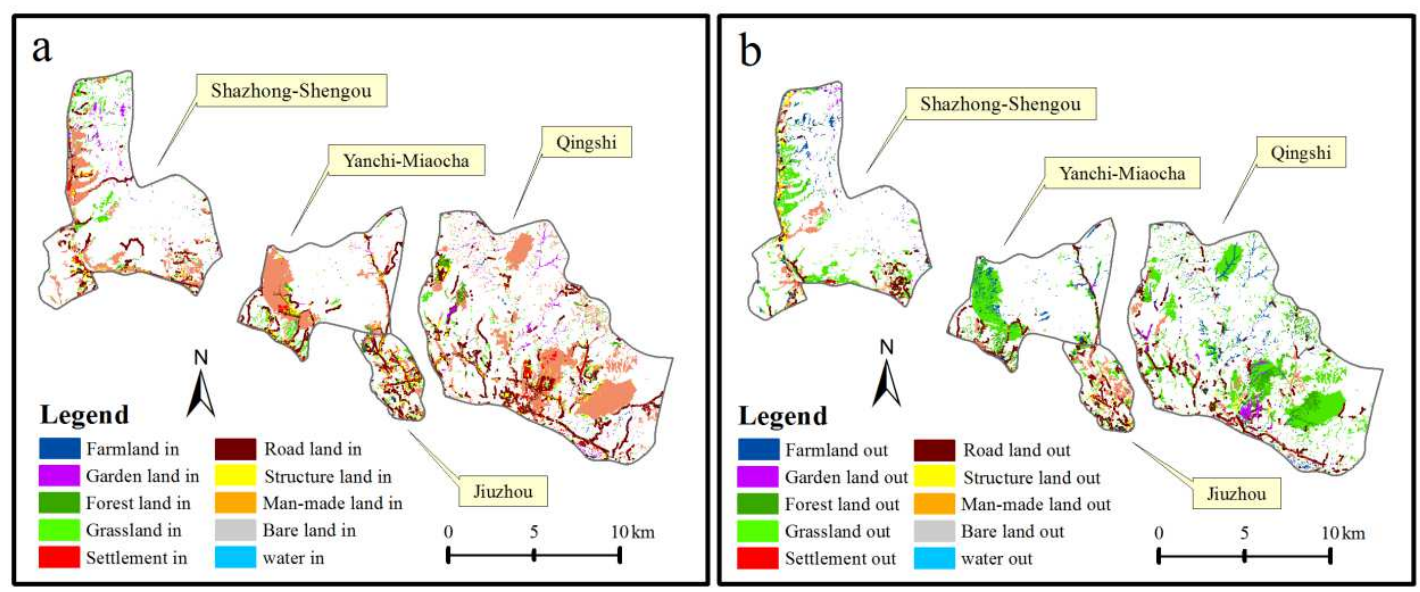

Fig.4 Transfer in and out of LULCC in key monitoring areas in 2000-2016
(a), Transferring in
(b), Transferring out

We also analyzed LULCC of the three key monitoring areas in the study region (Fig.4). In 2000-2016, the total area of LULCC in the key monitoring areas was $84.52 \mathrm{~km}^{2}$ (Table 2). According to the area of LULCC transfer-out, the largest to smallest were: grassland $>$ farmland $>$ garden land $>$ man-made land $>$ forest $>$ bare land $>$ structure $>$ building $>$ road $>$ water. Among them, grassland 
of $10.14 \mathrm{~km}^{2}$. Meanwhile, from LULCC transfer-in, the area from largest to smallest were: manmade land $>$ grassland $>$ structures $>$ buildings $>$ forest $>$ garden land $>$ road $>$ bare land $>$ farmland $>$ water. And the largest transfer-in type was man-made land with an area of $38.79 \mathrm{~km}^{2}$. The second and third were forest and grassland, with area of $13.76 \mathrm{~km}^{2}$ and $9.65 \mathrm{~km}^{2}$, respectively.

Table2 Transfer matrix of LULCC in key monitoring areas in 2000-2016 (unit: $\mathrm{km}^{2}$ )

\begin{tabular}{cccccccccccc}
\hline $\begin{array}{c}\text { Land } \\
\text { type }\end{array}$ & GRL & RL & BDL & FAL & SL & BL & FOL & MML & WA & GDL & Out \\
\hline GRL & - & 2.06 & 2.24 & 0.69 & 3.97 & 2.04 & 13.12 & 33.23 & 0.18 & 0.90 & 58.43 \\
RL & 0.24 & - & 0.03 & 0.01 & 0.07 & 0.00 & 0.07 & 0.12 & 0.00 & 0.01 & 0.55 \\
BDL & 0.14 & 0.07 & - & 0.02 & 0.24 & 0.00 & 0.04 & 0.19 & 0.00 & 0.00 & 0.70 \\
FAL & 3.50 & 0.18 & 0.65 & - & 0.50 & 0.02 & 0.12 & 2.22 & 0.01 & 2.94 & 10.14 \\
SL & 0.46 & 0.09 & 0.33 & 0.01 & - & 0.00 & 0.09 & 0.48 & 0.00 & 0.01 & 1.47 \\
BL & 0.71 & 0.02 & 0.02 & 0.00 & 0.03 & - & 0.00 & 0.83 & 0.00 & 0.00 & 1.62 \\
FOL & 1.97 & 0.25 & 0.17 & 0.04 & 0.42 & 0.01 & - & 0.72 & 0.00 & 0.03 & 3.60 \\
MML & 1.31 & 0.50 & 0.68 & 0.03 & 0.86 & 0.03 & 0.17 & - & 0.02 & 0.01 & 3.61 \\
WA & 0.05 & 0.00 & 0.00 & 0.00 & 0.01 & 0.00 & 0.01 & 0.06 & - & & 0.13 \\
GDL & 1.26 & 0.24 & 0.71 & 0.52 & 0.44 & 0.00 & 0.13 & 0.94 & 0.01 & - & 4.25 \\
In & 9.65 & 3.41 & 4.82 & 1.33 & 6.53 & 2.10 & 13.76 & 38.79 & 0.23 & 3.90 & 84.52 \\
\hline
\end{tabular}

$G R L=$ Grassland, $R L=$ Road land, $B D L=$ building land, $F A L=F a r m l a n d, S L=$ Structure land, $B L=$ Bare land, $F O L=F o r e s t$ land,

$M M L=$ Man-made land, $W A=$ Water, $G D L=$ Garden land

\subsection{The feature of new urban land reclamation from SEII and TNI}

According to the sites and scale of HRGFP (we only counted the plots with an area $\geq 2000 \mathrm{~km}^{2}$ ), in 2000-2010, about 412 sites were interpreted from aerial images in study region, which had an area of $35.55 \mathrm{~km}^{2}$ (Fig.5a), and increased by $3.56 \mathrm{~km}^{2}$ per year. In $2010-2016$, compared with the last ten years, 527 new and renew sites from HRGFP were interpreted, and their area was $132.58 \mathrm{~km}^{2}$ with a growth of $22.10 \mathrm{~km}^{2}$ per year, and most of them were renew plots on original sites (Fig. $5 \mathrm{~b}$ ).

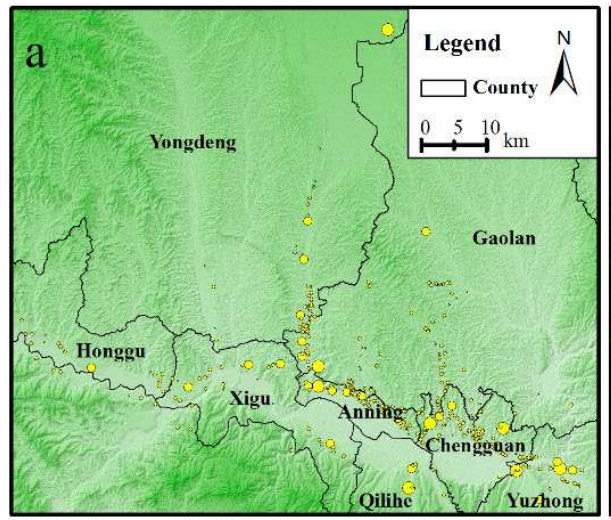

Area $\left(\mathrm{m}^{2}\right) \quad 2000-10000$

- $250000-1000000$ o $1000000-5000000$

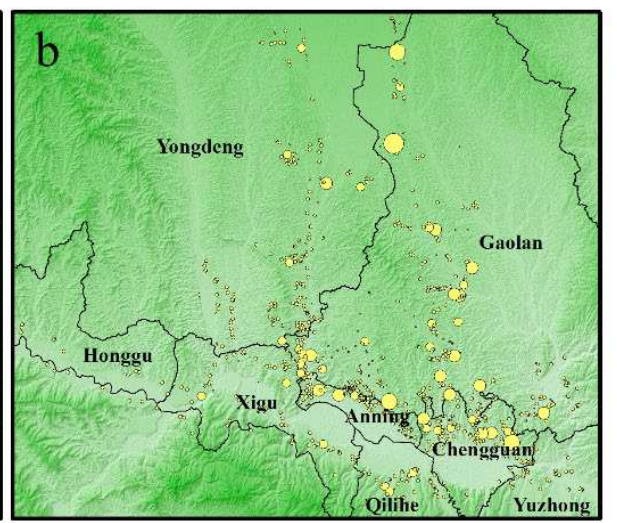

$10000-50000$ $50000-250000$ $5000000-25000000 \bigcirc 25000000-50000000$

Fig.5 The site and scale of land-creation (the center of yellow circle expresses the site of landcreation, and size indicated its scale).

(a), 2000-2010

(b), 2010-2016 
To analyze the overall trend of LULCC in our study region, we also calculated SEII of land types in 2000-2010 and 2010-2016 (Table3). In 2000-2010, the land types with relatively stability were farmland and garden land. Buildings, roads, structures, bare land, and water area showed relatively slower expansion in a short time. On the other hand, grassland contracted rapidly, and forest and man-made land quickly expanded, which indicated the obvious human activity on these land cover types, such as HRGFP and afforestation projects.

Table3 SEII of land types in 2000-2010

\begin{tabular}{cccccc}
\hline Land types & $\beta_{1}$ & $\beta_{2}$ & $\beta 1+\beta 2$ & $\beta 1-\beta 2$ & SEII grades \\
\hline Farmland & -0.55 & -0.43 & -0.98 & -0.12 & Relative stability \\
Garden land & -0.28 & -0.24 & -0.52 & -0.04 & Relative stability \\
Forest & 0.13 & -0.35 & -0.22 & 0.47 & Rapid expansion \\
Grassland & -7.62 & -6.75 & -14.37 & -0.87 & Rapid contraction \\
Settlement & -0.03 & -0.09 & -0.12 & 0.06 & Slower expansion \\
Road & -0.02 & -0.06 & -0.08 & 0.04 & Slower expansion \\
Structure & 0.01 & -0.08 & -0.08 & 0.09 & Slower expansion \\
Man-made land & 0.23 & -0.08 & 0.15 & 0.32 & Rapid expansion \\
Bare land & -0.06 & -0.11 & -0.17 & 0.04 & Slower expansion \\
Water land & -0.01 & -0.01 & -0.02 & 0.00 & Slower expansion \\
\hline
\end{tabular}

From 2010 to 2016, garden land and bare land were relatively stable. However, farmland, forest, and grassland showed rapid contraction, that is, these three land types were continuously transferout in this period. Meanwhile, water area showed a relatively slower expansion, while building, road, structure and man-made land all showed relatively rapid expansion (Table4), which also indicated that in this period the process of HRGFP was strengthening and urban expansion and construction was developing rapidly.

Table4 SEII of land types in 2010-2016

\begin{tabular}{cccccc}
\hline Land types & $\beta_{1}$ & $\beta_{2}$ & $\beta 1+\beta 2$ & $\beta 1-\beta 2$ & SEII grades \\
\hline Farmland & -0.81 & -0.45 & -1.26 & -0.36 & Rapid contraction \\
Garden land & -0.38 & -0.42 & -0.79 & 0.04 & Relative stability \\
Forest land & -1.34 & -1.19 & -2.53 & -0.16 & Rapid contraction \\
Grassland & -11.16 & -9.55 & -20.71 & -1.61 & Rapid contraction \\
Settlement & -0.07 & -0.23 & -0.31 & 0.16 & Rapid expansion \\
Road & -0.04 & -0.15 & -0.19 & 0.12 & Rapid expansion \\
Structure & -0.03 & -0.19 & -0.22 & 0.16 & Rapid expansion \\
Man-made land & 1.24 & -0.42 & 0.81 & 1.66 & Rapid expansion \\
Bare land & -0.24 & -0.23 & -0.47 & -0.02 & Relative stability \\
Water land & -0.02 & -0.03 & -0.05 & 0.00 & Slower expansion \\
\hline
\end{tabular}

TNI indicated that in 2000-2010, the distribution of new plots increased first and then decreased with the change of elevation, and most were at 1500-1800m. In 2010-2016, the area of new plots in elevation zones increased significantly and the maximum elevation interval was 1900 2000m. In 2000-2010, the new urban plot distribution was mainly concentrated on slopes of $0-5^{\circ}$, while in 2010-2016, they were mainly on slopes of $5-25^{\circ}$. We further graded TNI into seven classes (Table5) and found that the changes in TNI in 2000-2010 and 2010-2016 were basically the same 
and mainly concentrated in the TNI classes of 0.5-0.6 and 0.6-0.7. Combined with DEM and slope, we found that the two TNI classes were mainly located in the areas with relatively low elevation and steep slopes or relatively high elevation and shallow slopes.

Table5 TNI classes statistics in 2000-2010 and 2010-2016

\begin{tabular}{ccccccccc}
\hline \multicolumn{2}{c}{ TNI classes } & $0.3-0.4$ & $0.4-0.5$ & $0.5-0.6$ & $0.6-0.7$ & $0.7-0.8$ & $0.8-0.9$ & $0.9-1.0$ \\
\hline \multirow{2}{*}{$2000-2010$} & Area $\left(\mathrm{km}^{2}\right)$ & 0.416 & 1.705 & 12.693 & 20.64 & 0.077 & 0.001 & $/$ \\
& Percentage & 1.17 & 4.80 & 35.72 & 58.09 & 0.22 & 0.00 & $/$ \\
\hline \multirow{2}{*}{$2010-2016$} & Area $\left(\mathrm{km}^{2}\right)$ & 1.661 & 6.565 & 48.383 & 75.64 & 0.304 & 0.003 & $/$ \\
& Percentage & 1.25 & 4.95 & 36.50 & 57.06 & 0.23 & 0.01 & $/$ \\
\hline
\end{tabular}

\subsection{Environmental evaluation with RSEI}

To analyze the environmental quality in study region during HRGFP, based on Landsat TM/ETM+ images, we calculated NDVI, Humidity, LST, and BCI. The RSEI in 1991, 2001, 2009, and 2016 were obtained by PCA and further normalized to 0-1(Fig.6). The statistics found that RSEI average value from small to large were 2001,1991, 2009, and 2016 with value of 0.272, 0.297, 0.309, and 0.406, respectively. From 1991 to 2009 the environmental quality slightly decreased, then slowly increased, and substantial improved in 2009-2016. In 1991-2016, the proportion of the area with ecological grades of highest, high, and medium increased from $16.3 \%$ to $35.9 \%$, and the proportion of low and lowest decreased from $83.72 \%$ to $62.12 \%$ (Table6). The area with improved environmental quality in study area was about $3984 \mathrm{~km}^{2}$, or $55.73 \%$ of the total area, while the area with degraded environmental quality was only $565.8 \mathrm{~km}^{2}$, accounting for $7.91 \%$ of the total area.
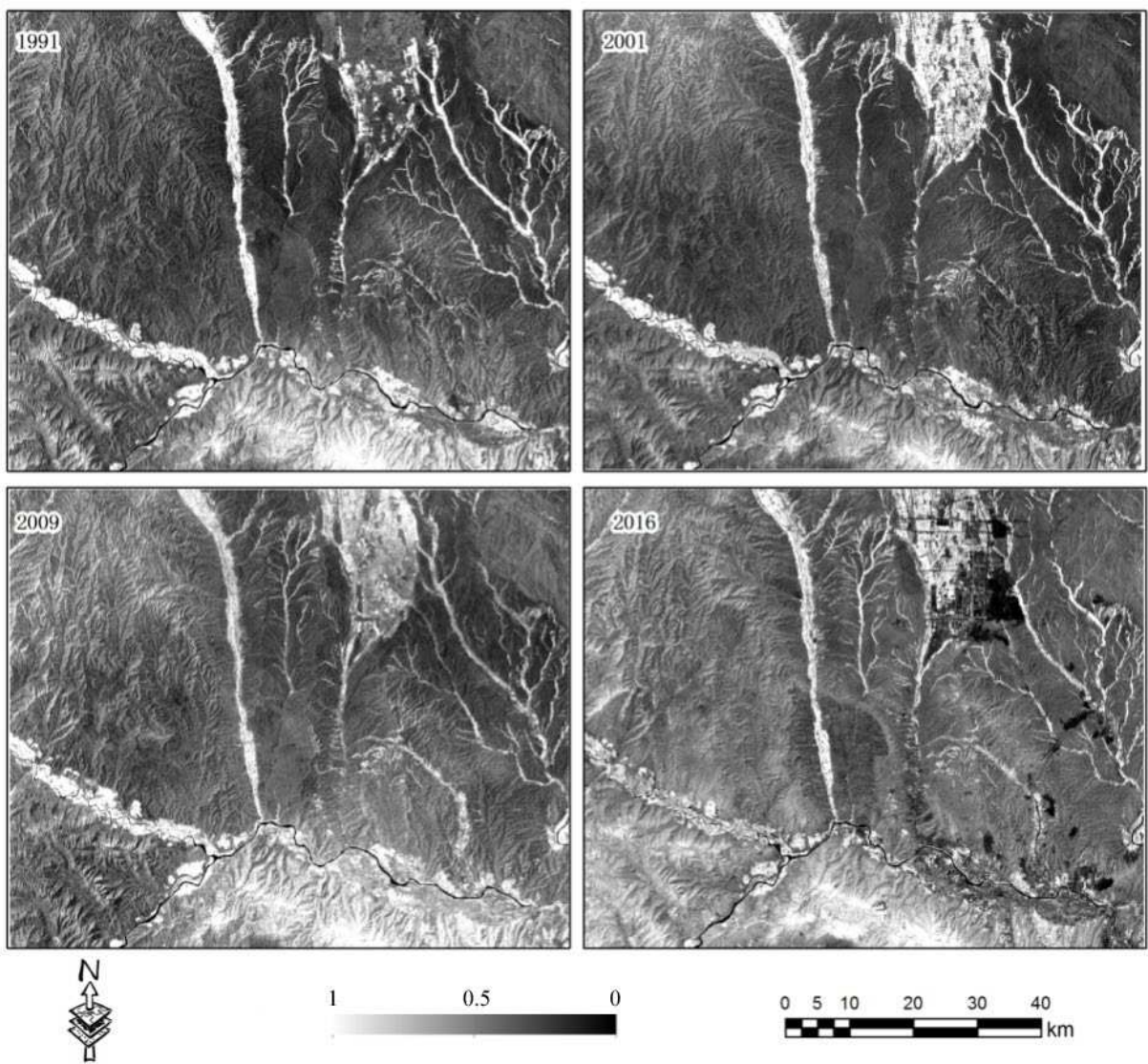

413

414

415

Fig.6 RSEI Trend in 1991-2016 


\begin{tabular}{|c|c|c|c|c|c|c|c|c|}
\hline \multirow[b]{2}{*}{ RSEI Grades } & \multicolumn{2}{|c|}{1991} & \multicolumn{2}{|c|}{2001} & \multicolumn{2}{|c|}{2009} & \multicolumn{2}{|c|}{2016} \\
\hline & $\begin{array}{l}\text { Area } \\
\left(\mathrm{km}^{2}\right)\end{array}$ & $\begin{array}{l}\text { PCT } \\
(\%)\end{array}$ & $\begin{array}{l}\text { Area } \\
\left(\mathrm{km}^{2}\right)\end{array}$ & $\begin{array}{l}\text { PCT } \\
(\%)\end{array}$ & $\begin{array}{l}\text { Area } \\
\left(\mathrm{km}^{2}\right)\end{array}$ & $\begin{array}{l}\text { PCT } \\
(\%)\end{array}$ & $\begin{array}{l}\text { Area } \\
\left(\mathrm{km}^{2}\right)\end{array}$ & $\begin{array}{l}\text { PCT } \\
(\%)\end{array}$ \\
\hline lower(0-0.2) & 3700.64 & 51.76 & 3765.64 & 52.67 & 2934.73 & 41.05 & 1408.30 & 19.70 \\
\hline $\operatorname{low}(0.2-0.4)$ & 2284.62 & 31.96 & 2306.46 & 32.26 & 2817.12 & 39.41 & 3175.56 & 44.42 \\
\hline medium(0.4-0.6) & 626.56 & 8.76 & 582.54 & 8.15 & 873.64 & 12.22 & 1727.48 & 24.16 \\
\hline $\operatorname{High}(0.6-0.8)$ & 302.31 & 4.23 & 272.94 & 3.82 & 356.26 & 4.98 & 584.16 & 8.17 \\
\hline Higher(0.8-1) & 235.31 & 3.29 & 221.85 & 3.10 & 167.68 & 2.35 & 253.93 & 3.55 \\
\hline
\end{tabular}

417

418

\section{Discussions}

\subsection{The role of local government in HRGFP}

Lanzhou is located in the long, narrow valley of the Yellow River Basin, and the Yellow River passes through the main city, forming a $50 \mathrm{~km}$ long east-west and narrow north-south strip city. With the development of urbanization, the contradiction between urban economic development and limited spatial expansion was very acute. The strategy from local government to deal with the quandary was to expand toward the unused land of barren hills of north, which is an effective mode to open up new space of construction land for urban and industrial development without or with less farmland. Therefore, the local government issued a series of measures to vigorously promote the development of the HRGFP. For example, in 1988, the Lanzhou government approved Jiuzhou Economic Development Zone, which was the beginning of the HRGFP. In 2004, the local government made its urban spatial expansion strategy of extending from east and west, and expanding from south and north, which thrust HRGFP into a period of rapid development. In 2007, the unused land around Lanzhou were actively promoted toward the comprehensive development and utilization. In 2012, the local government wrote the Scheme of Planning and Construction for the Comprehensive Development and Utilization of Wasteland such as low hills, gentle slopes, and gullies in Lanzhou, which was approved by the National Ministry of Land and Resources. After that was the fastest expansion year for the HRGFP (General Office of Lanzhou Municipal People's Government ,2014, 2016).

Our results showed that the new land reclamation and the effects of urban space expansion and economic development caused by HRGFP were apparent, which gradually developed subregions in stages. The LULCC Interpreted from remote sensing images also showed that more new land types, especially buildings, structures, and green parks have been built on the new urban land. The result was a new Lanzhou City that had become more spacious and prosperous.

\subsection{The protection of the environment in HRGFP}

Originally, the eco-environmental risk caused by land-creation projects drew the attention of the local government (Lanzhou bureau of land and resources, 2013). A series of regulations was issued by the Chinese government to effectively limit the eco-environmental risk caused by land-creation projects. According to the National Land Law, reclaiming unused land for another purpose must be scientifically evaluated. In 2013, the policy on further strengthening the management of urban dust was issued by the Lanzhou government, which required that the land reclamations must not be carried out without an environmental impact assessment (EIA). Due to the characteristics of Loess hills, the problems of eco-environmental risk in Lanzhou usually included construction dust, soil erosion, vegetation destruction, and farmland reduction. The premise of land-creation projects 
is to protect the eco-environment. Fortunately, some new effective technologies summarized from other projects in China were adopted in the Lanzhou land-creation projects (Ma, 2016; Zhang et al., 2009). For example, to prevent and control the dust, water-flushing operations, bare-soil coverings, and a prohibition on working on windy days effectively reduced the dust. Some reasonable construction procedures and silt dams were adopted to control soil erosion. With a series of policies, field investigations showed that about 806 geo-disasters and potentially dangerous events were avoided through the land-creation projects (Liu and Li, 2014). Moreover, some of new land types, such as forest, grassland, and farmland were increased to compensate the original loss in vegetation cover. Therefore, the influence on local eco-environment caused by land reclamations is still unclear, and the impact on geo-disasters also needs to be evaluated over the long term. Using RSEI and 26 years of time series images, we showed that the eco-environment in Lanzhou first declined and then slowly improved over the length of the land reclamations projects (Fig.8). That is, although landcreation projects would bring certain impact on the local environment in the early states, the urban expansion and economic development were immediate.

\section{Conclusions}

In the tide of urbanization in Lanzhou, China, land creation by hilltop removing and gully filling is a realistic model to solve the restriction of river-valley urban terrain. In this study, we mainly have monitored the process, changes in plot characteristics, and the eco-environmental impact of landcreation projects with remote sensing information technology rather than the suitability of land development and utilization and establishment of environmental impact assessment system. Our results from the latest multiple aerial remote sensing datasets and field investigation show that urban space expansion and economic development caused by land-creation projects is very apparent, with a continuous shift from the traditional urban area to the north where there were low hills, gentle slopes, and gullies. We found that large scale land-creation projects in Lanzhou mainly occurred in 2012-2016. During this period, a series of Chinese government policies and specifications were issued to greatly promote and guide the land-creation projects. Our field survey found that most of geo-disasters and hidden danger points in the study area were eliminated after the land-creation projects. Remote sensing images indicated that forest and grassland increased on the new plots in addition to buildings, which also enhanced the gradual improvement of local eco-environmental quality. Our results indicated that land-creation projects in Lanzhou were increasing urban space expansion and economic development, which also were leading to improved eco-environmental conditions under the guidance of the local government.

\section{ACKNOWLEDGMENTS}

This study was funded by the National Natural Science Foundation of China (Grant No. 41461084), Gansu surveying and mapping institute of China(GSBSM-2017-01-08), the PhD Programs Foundation of Lanzhou University of Technology.

\section{References}

Al-Sharif, A.A., Pradhan, B., Shafri, H.Z.M., \& Mansor, S. (2014). Quantitative analysis of urban sprawl in Tripoli using Pearson's Chi-Square statistics and urban expansion intensity index. In, IOP Conference Series: Earth and Environmental Science (p. 012006): IOP Publishing

Baig, M.H.A., Zhang, L., Shuai, T., \& Tong, Q. (2014). Derivation of a tasselled cap transformation based on Landsat 
Chen, L., Sun, Y., \& Sajjad, S. (2018). Monitoring and predicting land use and land cover changes using remote sensing and GIS techniques-A case study of a hilly area, Jiangle, China. PloS one, 13

Deng, C., \& Wu, C. (2012). BCI: A biophysical composition index for remote sensing of urban environments. Remote Sensing of Environment, 127, 247-259

Dobrovolný, P. (2013). The surface urban heat island in the city of Brno (Czech Republic) derived from land surface temperatures and selected reasons for its spatial variability. Theoretical Applied Climatology, 112, 89-98

Fischer, G., Hizsnyik, E., Prieler, S., van Velthuizen, H., \& Wiberg, D. (2012). Scarcity and abundance of land resources: competing uses and the shrinking land resource base

Fisher, A., Flood, N., \& Danaher, T. (2016). Comparing Landsat water index methods for automated water classification in eastern Australia. Remote Sensing of Environment, 175, 167-182

General Office of Lanzhou Municipal People's Government (2014). Notice on the supplementary program of farmland for the pilot project of comprehensive development and utilization of unused land such as low hills, gentle slopes, gullies and ditches in lanzhou. Lanzhou Political News, 27-28

General Office of Lanzhou Municipal People's Government (2016). The general office of lanzhou municipal people's government issued a notice on the administrative measures for the pilot project of comprehensive development and utilization of unused land such as low hills, gentle slopes, gullies and ditches in lanzhou (trial). Lanzhou Political News, 21-24

Green, K., Kempka, D., \& Lackey, L. (1994). Using remote sensing to detect and monitor land-cover and land-use change. Photogrammetric engineering remote sensing, 60, 331-337

Gupta, K., Kumar, P., Pathan, S.K., \& Sharma, K.P. (2012). Urban Neighborhood Green Index-A measure of green spaces in urban areas. Landscape Urban Planning, 105, 325-335

Hang, M.Q., Ji, S.N., \& Sun, N.X. (2009). The Major Environmental Impacts and Preventable Countermeasures fortheLand Construction Project in Lanzhou. Journal of Arid Land Resources and Environment, 23(3):77-82(In Chinese)

Hassan, Z., Shabbir, R., Ahmad, S.S., Malik, A.H., Aziz, N., Butt, A., \& Erum, S. (2016). Dynamics of land use and land cover change (LULCC) using geospatial techniques: a case study of Islamabad Pakistan. SpringerPlus, 5, 812

Jing, Y., Zhang, F., He, Y., Johnson, V.C., \& Arikena, M. (2020). Assessment of spatial and temporal variation of ecological environment quality in Ebinur Lake Wetland National Nature Reserve, Xinjiang, China. Ecological Indicators, 110, 105874

Lanzhou bureau of land and resources (2013). Environmental impact assessment notice of the general plan for the comprehensive development and utilization of waste land such as low hills, gentle slopes and gullies in lanzhou. http://www.lzgtj.gov.cn/. 2013-05-07

Li, F., Chang, Q., Shen, J., \& Liu, J. (2015). Dynamic monitoring of ecological environment in loess hilly and gully region of Loess Plateau based on remote sensing: A case study on Fuxian County in Shaanxi Province. Northwest China. Ying yong sheng tai xue bao, 26, 3811-3817

Li, L., Li, J., Jiang, Z., Zhao, L., \& Zhao, P. (2018). Methods of population spatialization based on the classification information of buildings from china's first national geoinformation survey in urban area: A case study of Wuchang district, Wuhan city, China. Sensors, 18, 2558

Li, P., Qian, H., \& Wu, J. (2014). Accelerate research on land creation. Nature, 510, 29-31

Li, Y., Li, Y., Karácsonyi, D., Liu, Z., Wang, Y., \& Wang, J. (2020). Spatio-temporal pattern and driving forces of construction land change in a poverty-stricken county of China and implications for poverty-alleviation-oriented land use policies. Land Use Policy, 91, 104267 
Liu, T., Liu, H., \& Qi, Y. (2015). Construction land expansion and cultivated land protection in urbanizing China Insights from national land surveys, 1996-2006. Habitat International, 46, 13-22

Liu, Y., Peng, J., Zhang, T., \& Zhao, M. (2016). Assessing landscape eco-risk associated with hilly construction land exploitation in the southwest of China: trade-off and adaptation. Ecological Indicators, 62, 289-297

Liu, Y.S., \& Li, Y.H. (2014). Environment: China's land creation project stands firm. Nature, 511(7510):410

Liu, Z., Yang, X., He, H., \& Zhu, Q. (2013). Study on Macroscopical Dynamic Monitoring of New Increased Construction Land in Yinchuan Plain based on $20 \mathrm{~m}$ Scale Middle Resolution Remote Sensing Data. IERI Procedia, 5, 75-80

Ma, L. (2016). Debate and Thinking about the Ecological Impact of "Bulldoze Mountains to Build New City": A Case Study of

Lanzhou New City Ecology and Environment, 31, 85-90

Moulds, S., Buytaert, W., \& Mijic, A. (2015). An open and extensible framework for spatially explicit land use change modelling: the lulcc R package. Geosci Model Dev, 8 (10):, 3215-3229

Mundia, C.N., \& Aniya, M. (2005). Analysis of land use/cover changes and urban expansion of Nairobi city using remote sensing and GIS. International Journal of Remote Sensing, 26, 2831-2849

NASA (2016). Landsat8 (L8) data users hand book [EB/OL]. 2016-03-29[2016-04-20]. http://landsat.usgs.gov/documents/Landsat8 Data Users Hand book.pdf.

Niu, Q., Xiao, X., Zhang, Y., Qin, Y., Dang, X., Wang, J., Zou, Z., Doughty, R.B., Brandt, M., \& Tong, X. (2019). Ecological engineering projects increased vegetation cover, production, and biomass in semiarid and subhumid Northern China. Land Degradation Development, 30, 1620-1631

Niu, S., Zhao, C., Zhang, X., \& Ding, Y. (2010). Characteristics of household energy consumption and emissions reduction of structure conversion in Lanzhou City. Resources Science, 7

Olorunfemi, I.E., Fasinmirin, J.T., Olufayo, A.A., \& Komolafe, A.A. (2018). GIS and remote sensing-based analysis of the impacts of land use/land cover change (LULCC) on the environmental sustainability of Ekiti State, southwestern Nigeria. Environment, Development Sustainability, 1-32

Pan, J. (2016). Area delineation and spatial-temporal dynamics of urban heat island in Lanzhou City, China using remote sensing imagery. Journal of the Indian society of remote sensing, 44, 111-127

Pettorelli, N., Vik, J.O., Mysterud, A., Gaillard, J.-M., Tucker, C.J., \& Stenseth, N.C. (2005). Using the satellitederived NDVI to assess ecological responses to environmental change. Trends in ecology evolution, 20, 503-510

Pu, X., Wang, L., Wu, Z., Liu, H., Zhao, W., Ma, L., \& Ren, D. (2016). Engineering Geological Problems of Loess High Excavation Slope in Loess Hilly ad Gully Region of Lanzhou and Its Stability Analysis. China Earthquake Engineering Journal, 38, 787-794

Rao, W., Zhang, J., Xiao, H., \& Zhou, Q. (2007). Distribution Characteristics and Dynamic Change of Suburb Landscape Based on the Terrain Niche. Journal of South China Agricultural University, 16

Sobrino, J.A., Jiménez-Muñoz, J.C., \& Paolini, L. (2004). Land surface temperature retrieval from LANDSAT TM 5. Remote Sensing of environment, 90, 434-440

Steduto, P., Hsiao, T.C., Fereres, E., \& Raes, D. (2012). Crop yield response to water. fao Rome

Wen, J.H. (2016). Why Some Cities have to enlarge by Cutting Hills? Journal of Capital University of Economics and Bussiness, 18, 77-87

Wen, L., Butsic, V., Stapp, J.R., \& Zhang, A. (2018). What happens to land price when a rural construction land market legally opens in China? A spatiotemporal analysis of Nanhai district from 2010 to 2015. China Economic Review

Wu, S., \& Fu, X. (2017). Risk assessment and control method of debris flow in CheGou of ShenNongJia forest area. Advances in Geoscience, 1 
Xu, X., Cai, H., Sun, D., Hu, L., \& Banson, K. (2016). Impacts of mining and urbanization on the Qin-Ba Mountainous environment, China. Sustainability, 8, 488

Yang, X., Zhu, Y., Zhou, Y., Yang, X., \& Shi, Z. (2016). Time-space monitoring and stability analysis of high fill slope slip process at a airport in mountain region. Chinese Journal of Rock Mechanics and Engineering, 35, 3977-3990

Yang, Z., \& Wang, B. (2014). Progress in techniques of improvement and utilization of saline-alkali land in China and its future trend. Soil Water Conserv, 2, 1-11

Yu, H., Zeng, H., \& Jiang, Z. (2001). Study on distribution characteristics of landscape elements along the terrain gradient. Scientia geographica sinica, 21, 64-69

Yu, X., Guo, X., \& Wu, Z. (2014). Land surface temperature retrieval from Landsat 8 TIRS - Comparison between radiative transfer equation-based method, split window algorithm and single channel method. Remote Sensing, 6, 9829-9852

Yu, X., Zhu, B., Fan, S., Yin, Y., \& Bu, X. (2009). Ground-based observation of aerosol optical properties in Lanzhou, China. Journal of Environmental Sciences, 21, 1519-1524

Zhang, M., Ji, S., \& Sun, N. (2009). The Major Environmental Impacts and Preventable Countermeasures for the Land Construction Project in Lanzhou. Journal of Arid Land Resources and Environment, 23, 77-82

Zhou, G., \& He, Y. (2006). Characteristics and Influencing Factors of Urban Land Expansion in Changsha. Acta Geographica Sinica, 11

Zoungrana, B.J., Conrad, C., Amekudzi, L.K., Thiel, M., Da, E.D., Forkuor, G., \& Löw, F. (2015). Multi-temporal landsat images and ancillary data for land use/cover change (LULCC) detection in the Southwest of Burkina Faso, West Africa. Remote Sensing, 7, 12076-12102 


\section{Figures}

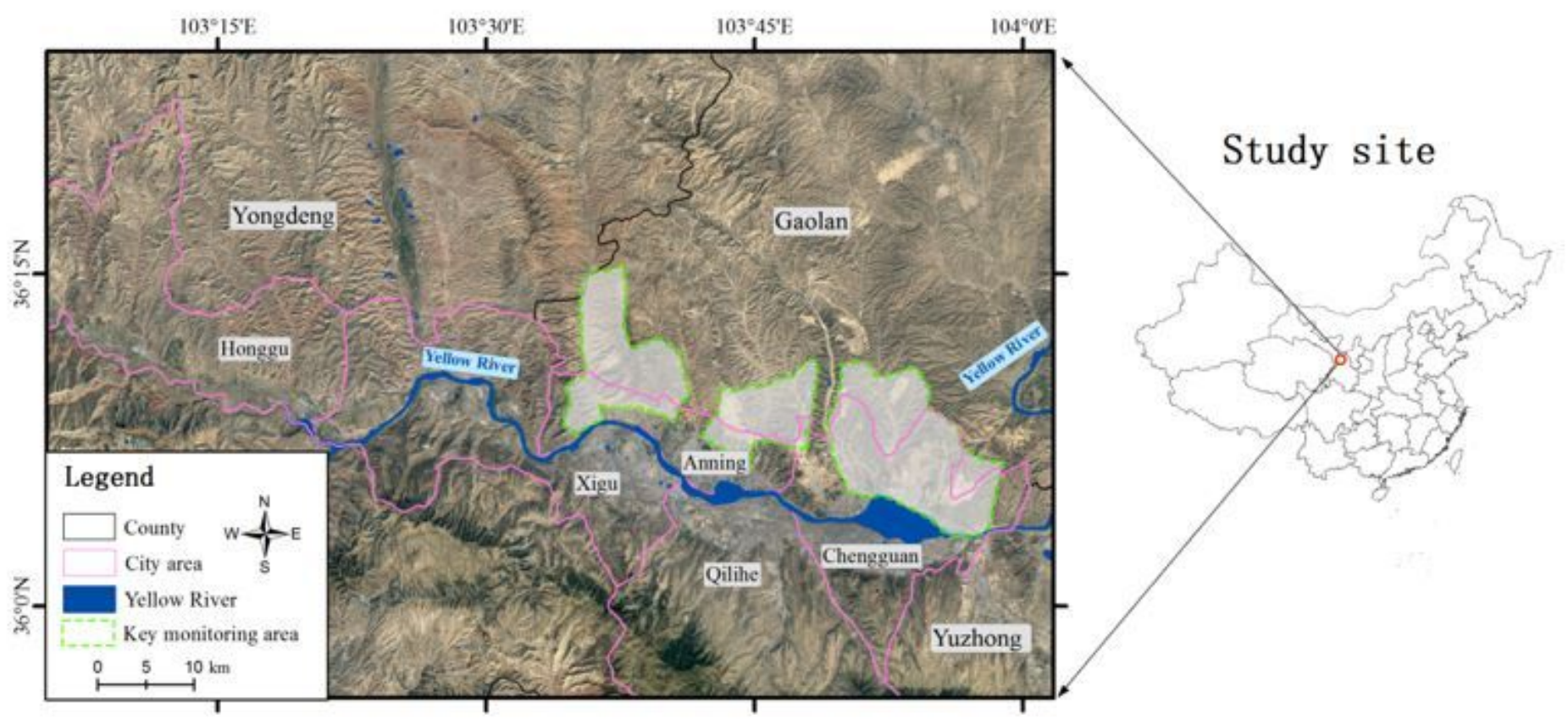

\section{Figure 1}

Study area (mainly including three counties (Yongdeng, Gaolan, and Yuzhong) and five districts (urban area: including Chengguan, Qilihe, Anning, Xigu, and Honggu). The areas with a green line are the key monitoring areas, from west to east are Shazhong-Shengou, Yanchi-Maocha-Jiuzhou, and Qingshi, respectively.) Note: The designations employed and the presentation of the material on this map do not imply the expression of any opinion whatsoever on the part of Research Square concerning the legal status of any country, territory, city or area or of its authorities, or concerning the delimitation of its frontiers or boundaries. This map has been provided by the authors. 


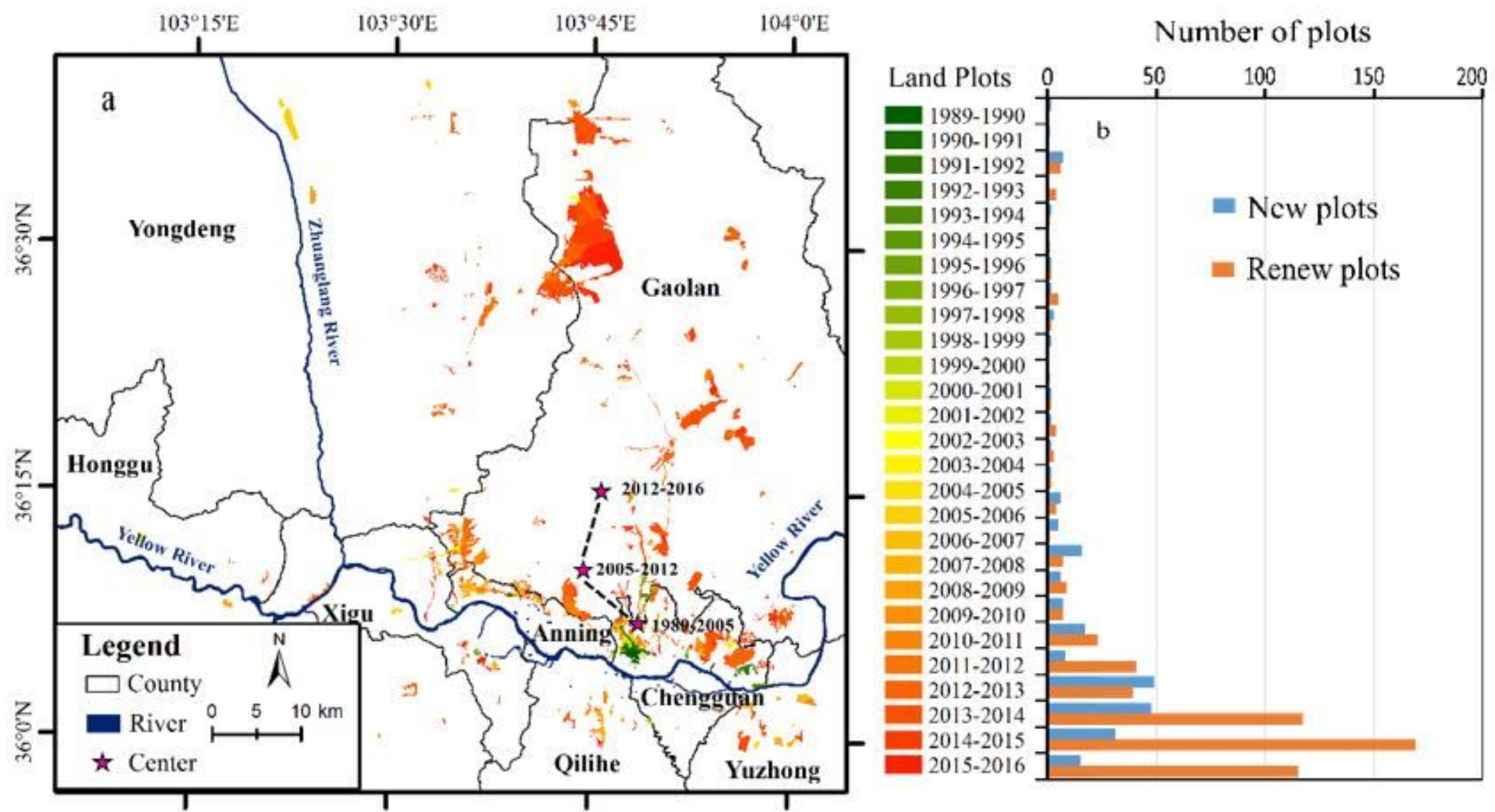

Figure 2

Spatial-temporal distribution and statistics of new land reclamation in 1989-2016 (a, Spatial distribution, three stars from south to north express the centers of new plots in 1989-2005, 2006-2012 and 2013-2016, respectively. $b$, The number of new and renew urban plots). Note: The designations employed and the presentation of the material on this map do not imply the expression of any opinion whatsoever on the part of Research Square concerning the legal status of any country, territory, city or area or of its authorities, or concerning the delimitation of its frontiers or boundaries. This map has been provided by the authors. 


\subsection{LULCC transfer analysis in 2000-2017}

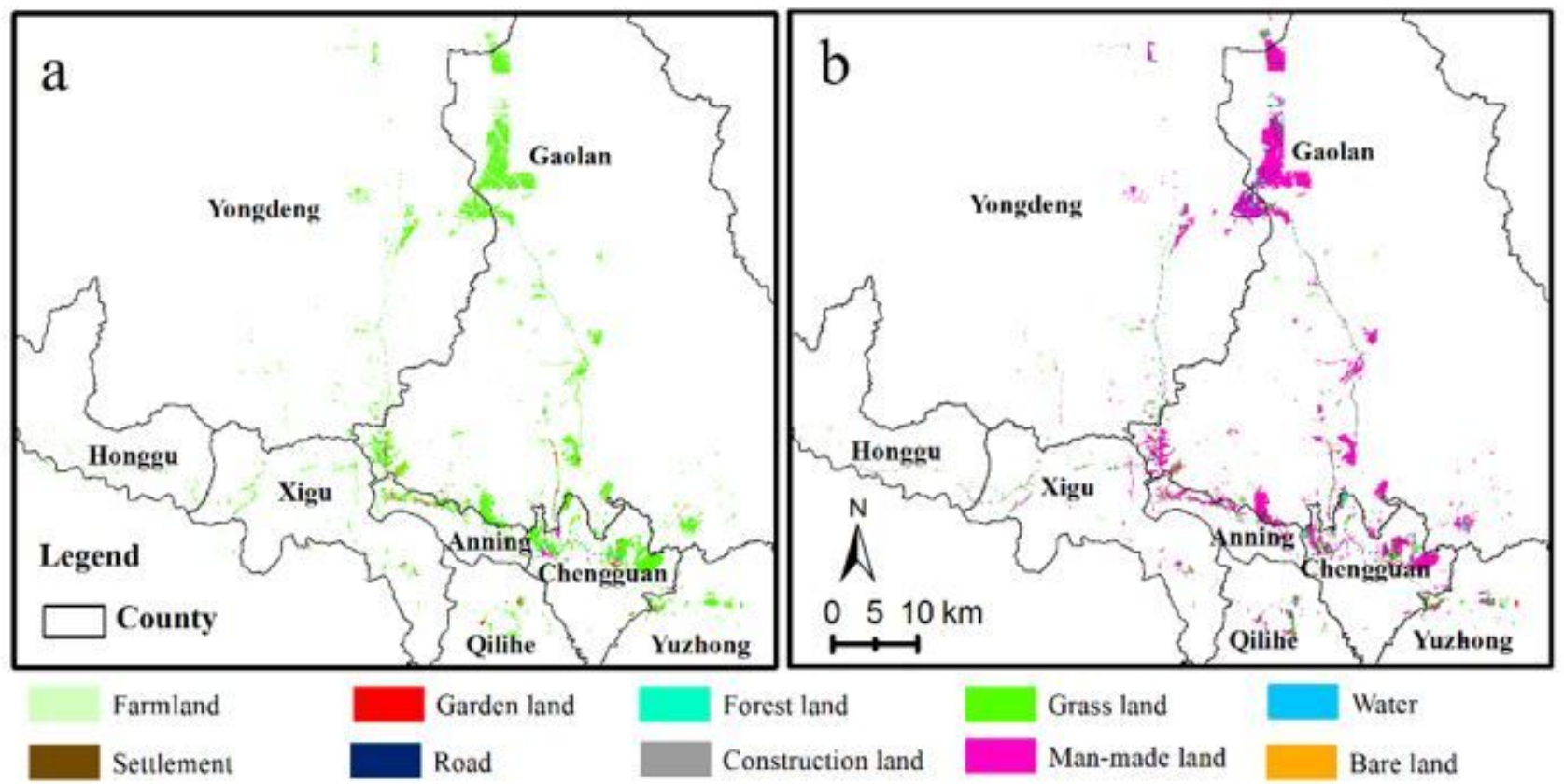

\section{Figure 3}

LULCC transfer and distribution in 2000-2017 (a), LULCC before 2010; (b), LULCC after 2010. Note: The designations employed and the presentation of the material on this map do not imply the expression of any opinion whatsoever on the part of Research Square concerning the legal status of any country, territory, city or area or of its authorities, or concerning the delimitation of its frontiers or boundaries. This map has been provided by the authors.
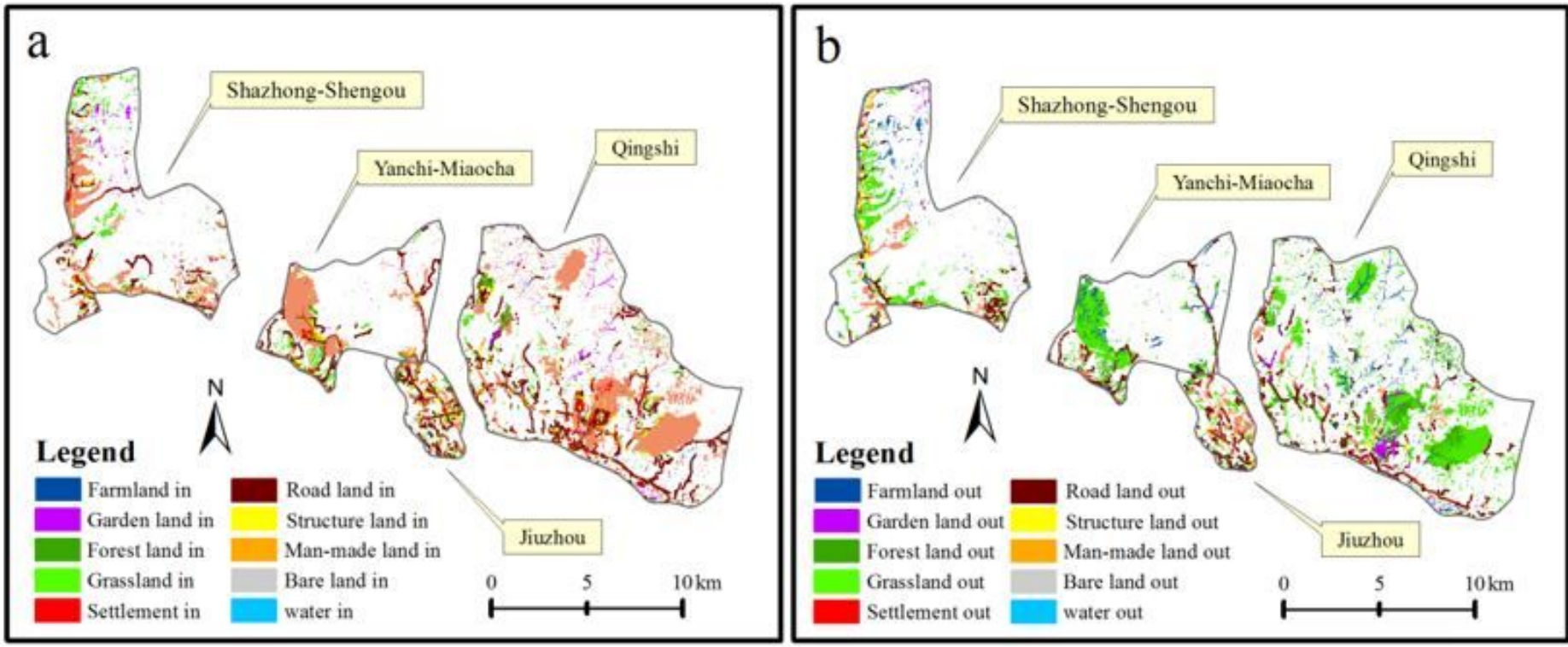

Figure 4 
Transfer in and out of LULCC in key monitoring areas in 2000-2016 (a), Transferring in (b), Transferring out. Note: The designations employed and the presentation of the material on this map do not imply the expression of any opinion whatsoever on the part of Research Square concerning the legal status of any country, territory, city or area or of its authorities, or concerning the delimitation of its frontiers or boundaries. This map has been provided by the authors.

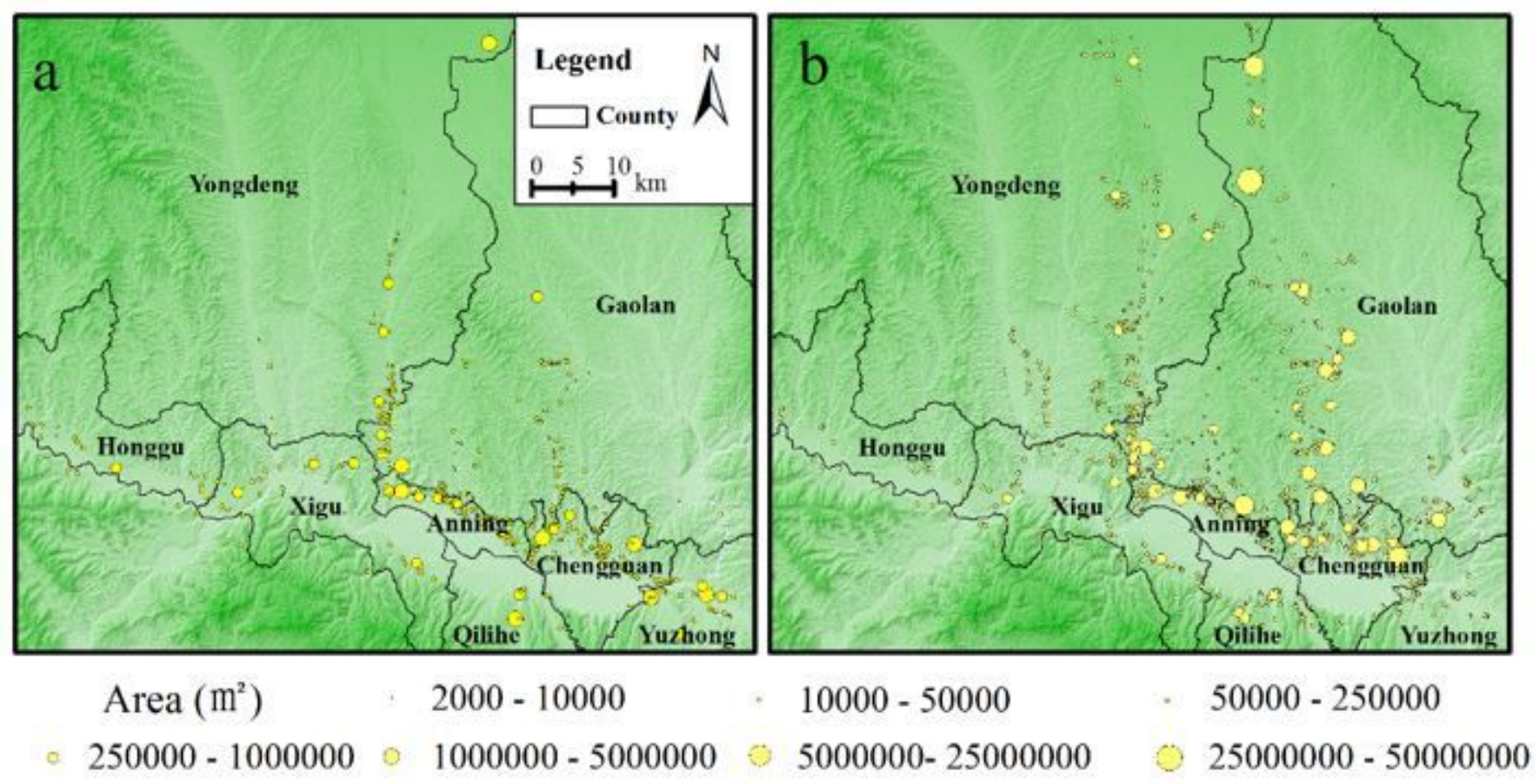

\section{Figure 5}

The site and scale of land-creation (the center of yellow circle expresses the site of land-creation, and size indicated its scale). (a), 2000-2010 (b), 2010-2016. Note: The designations employed and the presentation of the material on this map do not imply the expression of any opinion whatsoever on the part of Research Square concerning the legal status of any country, territory, city or area or of its authorities, or concerning the delimitation of its frontiers or boundaries. This map has been provided by the authors. 

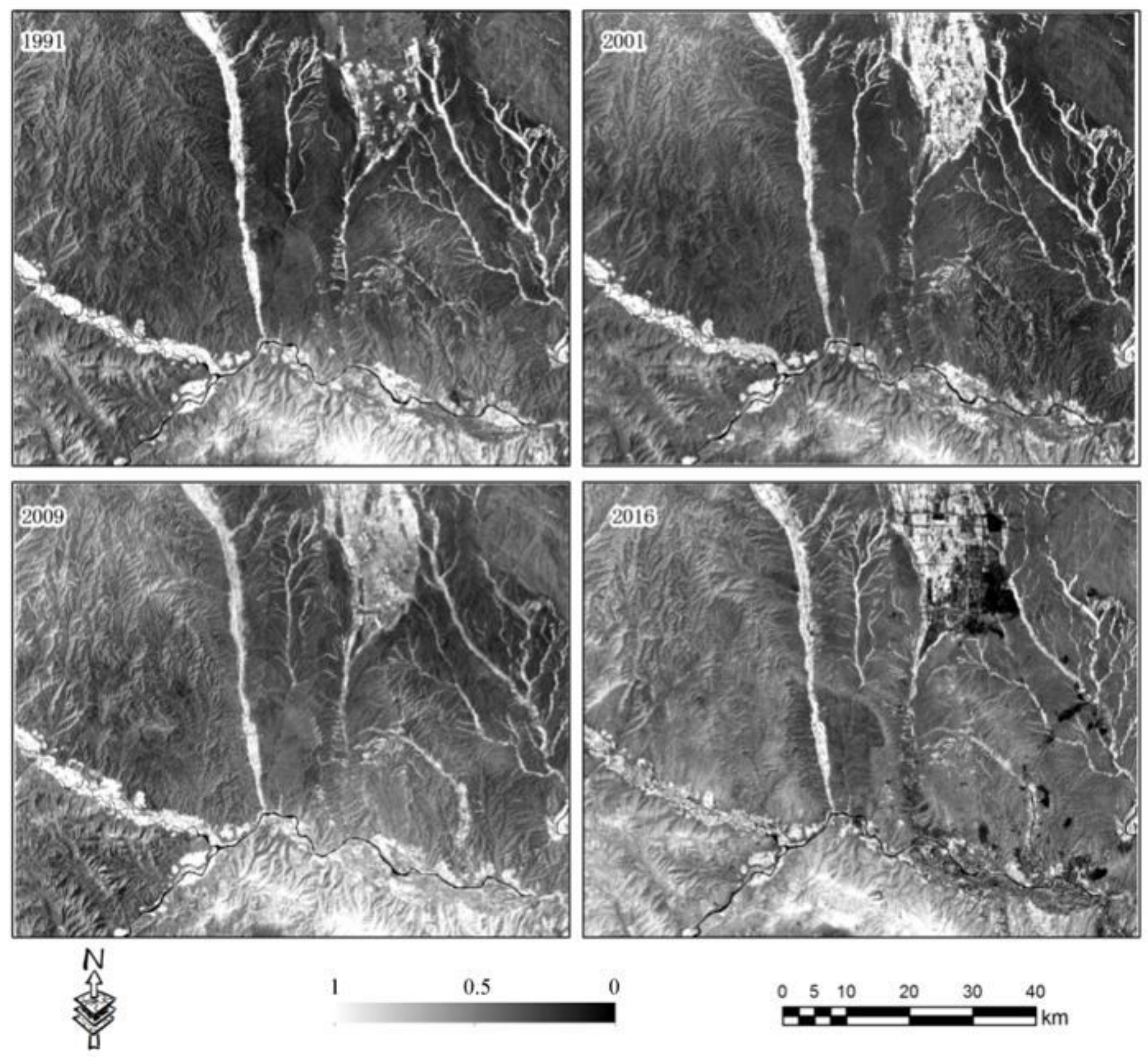

0.5

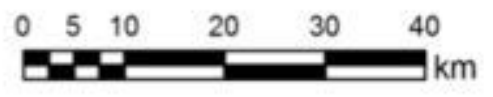

Figure 6

RSEl Trend in 1991-2016 